\title{
Epidemiology of malaria and chloroquine resistance in Mizoram, northeastern India, a malaria-endemic region bordering Myanmar
}

\author{
Rita Zomuanpuii ${ }^{*} \mathbb{E}$, Christopher L. Hmar², Khawlhring Lallawmzuala ${ }^{3}$, Lal Hlimpuia ${ }^{4}$, \\ Praveen Balabaskaran Nina ${ }^{5}$ and Nachimuthu Senthil Kumar ${ }^{1}$
}

\begin{abstract}
Background: Mizoram, a northeastern state in India, shares international borders with Myanmar and Bangladesh and is considered to be one of the key routes through which drug-resistant parasites of Southeast Asia enter mainland India. Despite its strategic location and importance, malaria epidemiology and molecular status of chloroquine resistance had not been well documented, and since chloroquine (CQ), as the first-line treatment in Plasmodium falciparum infection was discontinued since 2008, it was expected that CQ-sensitive haplotype would be more abundant.

Methods: Malaria epidemiology data for the period 2010 to 2018 was collected from the office of State Vector Disease Control Programme. Plasmodium falciparum-positive blood samples were collected from government district hospitals, community health centres, primary health centres, sub-centres, and diagnostic centres from six malariaprone districts. The samples were processed and analysed using genes-P. falciparum chloroquine-resistant transporter (pfcrt) and P. falciparum multidrug resistance 1 (pfmdr1) via sequencing of PCR amplicon from 2015 to 2017.

Results: Malaria occurred throughout the year and $P$. falciparum accounted for $>89 \%$ of total malaria cases. During 2010-2018, the highest number of malaria incidence was recorded in Lawngtlai (36\% of total malaria cases; average $\mathrm{API}_{2010-2018}$ of 34.8) while Champhai remained consistently low (0.4\%; average $\mathrm{API}_{2010-2018}$ of 0.04$)$. Males of $\geq 15$ years old contributed maximum (35.7\%) among gender and age malarial distribution recorded during 2014-2018. Death due to malaria gradually decreased over the years. A higher abundance of mutated pfcrt ( $58.5 \%$ of the total sample analysed) and a lower prevalence of mutated pfmdr1 (48.7\%) were observed. All mutations identified for pfcrt belong to the Southeast Asian CVIET haplotype. Only a single point mutation was observed at $86(\mathrm{~N} \rightarrow \mathrm{Y})$ position in pfmdr1 (48.7\%). The key N86Y mutation in pfmdr1 that had been shown to modulate CQR was found in $67.1 \%$ of the samples positive for the CVIET haplotype.

Conclusions: This is the first report that details malaria epidemiology and also the molecular status of CQ-resistance in P. falciparum population of the region. The efforts of the State Vector Borne Disease Control Programme have proved to be quite effective in controlling the malaria burden in the state. Despite the discontinuation of CQ for a decade, local P. falciparum is observed with decreased CQ-sensitive haplotype. It is believed that the present findings will form a basis for further studies on genetic diversity in $P$. falciparum, which could confer better understanding of the complexity of the disease in Southeast Asia.
\end{abstract}

\footnotetext{
*Correspondence: rita_zoye@live.com

1 Department of Biotechnology, Mizoram University, Aizawl, Mizoram, India

Full list of author information is available at the end of the article
}

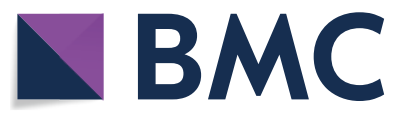

(c) The Author(s) 2020. This article is licensed under a Creative Commons Attribution 4.0 International License, which permits use, sharing, adaptation, distribution and reproduction in any medium or format, as long as you give appropriate credit to the original author(s) and the source, provide a link to the Creative Commons licence, and indicate if changes were made. The images or other third party material in this article are included in the article's Creative Commons licence, unless indicated otherwise in a credit line to the material. If material is not included in the article's Creative Commons licence and your intended use is not permitted by statutory regulation or exceeds the permitted use, you will need to obtain permission directly from the copyright holder. To view a copy of this licence, visit http://creativeco mmons.org/licenses/by/4.0/. The Creative Commons Public Domain Dedication waiver (http://creativecommons.org/publicdomain/ zero/1.0/) applies to the data made available in this article, unless otherwise stated in a credit line to the data. 
Keywords: Mizoram, Plasmodium falciparum, Chloroquine resistance, pfcrt, pfmdr1

\section{Background}

Malaria transmission in India occurs predominantly either as Plasmodium falciparum or Plasmodium vivax infections. India and 15 sub-Saharan African countries are estimated to carry $80 \%$ of malaria burden across the world in 2018 [1]. In India, 0.84 million malaria cases were reported in 2017, of which North Eastern $(\mathrm{NE})$, Eastern and Central Indian regions contributed 80\% of the total cases [2]. Mizoram, along with Assam, Arunachal Pradesh, Tripura, Manipur, Mizoram, Sikkim and Meghalaya form the eight NE States of India. NE India accounts for $4 \%$ of the population but contributed $6.6 \%$ of malaria cases and $25 \%$ of malaria mortality in India in 2018 [3].

Mizoram is a landlocked state in NE India with an estimated population of 1 million in the 2018 Census. Mizoram extends between latitude $21^{\circ} 58^{\prime} \mathrm{N}$ to $24^{\circ} 35^{\prime} \mathrm{N}$ and longitude $92^{\circ} 15^{\prime} \mathrm{E}$ to $93^{\circ} 29^{\prime} \mathrm{E}$, and altitude ranges from 500 to $2157 \mathrm{~m}$. Mizoram is under the direct influence of southwest monsoon characterized by wet summers $\left(18-33{ }^{\circ} \mathrm{C}\right)$ and dry winters $\left(11-24{ }^{\circ} \mathrm{C}\right)$ [4]. The state lies within the Indo-Burma region, one of the four biodiversity hotspots of India. The eastern and western regions of Mizoram share international borders with Myanmar and Bangladesh, respectively and shares domestic borders with Manipur, Assam and Tripura. The porous border with Myanmar could be one of the major entry routes of drug-resistant parasites to mainland India.

In 1973, the first cases of $P$. falciparum chloroquine resistance (CQR) were reported from Karbi Anglong district in Assam [5]. In the early 1980s, CQR was reported in Mizoram [6]. Most likely, CQR has spread from Southeast Asia (SEA) to the Indian mainland through NE India [7]. Treatment failures to sulfadoxine/pyrimethamine (SP) were first reported in NE India in 2005 [8] and molecular evidence to its resistance in $P$. falciparum was reported in $2013[9,10]$. This ushered in a change in the national drug policy of India; artesunate plus sulfadoxine-pyrimethamine (SP) has been replaced by a coformulated tablet of artemether-lumefantrine $(\mathrm{AL})$ in $\mathrm{NE}$ India since 2013 [11].

Within the 72 to 76 amino acid loci of $P$. falciparum chloroquine resistant transporter gene ( $p f c r t)$, the chloroquine-sensitive (CQS) strains have been marked with CVMNK allele [12], while polymorphism within this locus conferring CQR [13] is characterized by CVIET and CVIDT in parts of SEA and Indochina, respectively [14], SVMNT in Africa [15], and CVMNT in South America [16, 17]. In addition, 32-point mutations in $p f c r t$ have been identified to date and of these 11 are associated with CQR. Worldwide, K76T is considered to be the major molecular marker and a key determinant of $C Q R$ [18]. CQR, mediated by pfcrt mutations, has been shown to be modulated by mutations in P. falciparum multidrug resistance gene-1 (pfmdr1). Among the five (N86Y, Y184F, S1034C, N1042D, D1246Y) $m d r 1$ mutations, N86Y and Y184F have been linked with CQR [19-21].

Because the molecular status of CQR in P. falciparum in Mizoram remained poorly documented, the present study aimed at screening for polymorphisms within the genes linked to CQR (pfcrt and pfmdr1) across Mizoram. Additionally, the study aimed to present malaria epidemiology from 2010 to 2018. Due to the discontinuation of CQ as the first-line P. falciparum treatment in 2008, it was expected that the prevalence of CQS strain would be more abundant than $\mathrm{CQR}$ haplotype.

\section{Methods \\ Epidemiology data}

Mizoram is divided into 8 districts: Aizawl, Lunglei, Kolasib, Mamit, Lawngtlai, Champhai, Saiha, and Serchhip (Fig. 1). Available monthly and annual records of malaria (P. falciparum and P. vivax), including the number of deaths due to malaria ( $P$. falciparum and $P$. vivax combined) and anti-malarial drug treatment for $P$. falciparum were collected from the office of the State Vector Borne Disease Control Programme (SVBDCP) for the 8 districts of Mizoram from 2010 to 2018 (Fig. 1). Malaria case distribution was further categorized into gender (proportion of males and female), age (0-4 years, 5-14 years and 15+years; as recorded and available in SVBDCP records), passive case detection (PCD) i.e., febrile patients suspecting malaria seeking medical confirmation), and pregnancy infections.

\section{Sample collection}

From 2015 to 2017, confirmed P. falciparum-positive blood samples were collected from government district hospitals, community health centres, primary health centres, sub-centres, and diagnostic centres of Aizawl, Lunglei, Saiha, Kolasib, Mamit, Lawngtlai, and Serchhip districts (Champhai district was excluded for sample collection due to its consistently low annual parasite incidence (API) (Fig. 1). Samples were collected after obtaining consent from patients and guardians. For patients under 10 years of age, consent was obtained from their guardians (i.e., either one or both parents present at the time of blood sampling). Details regarding new or 


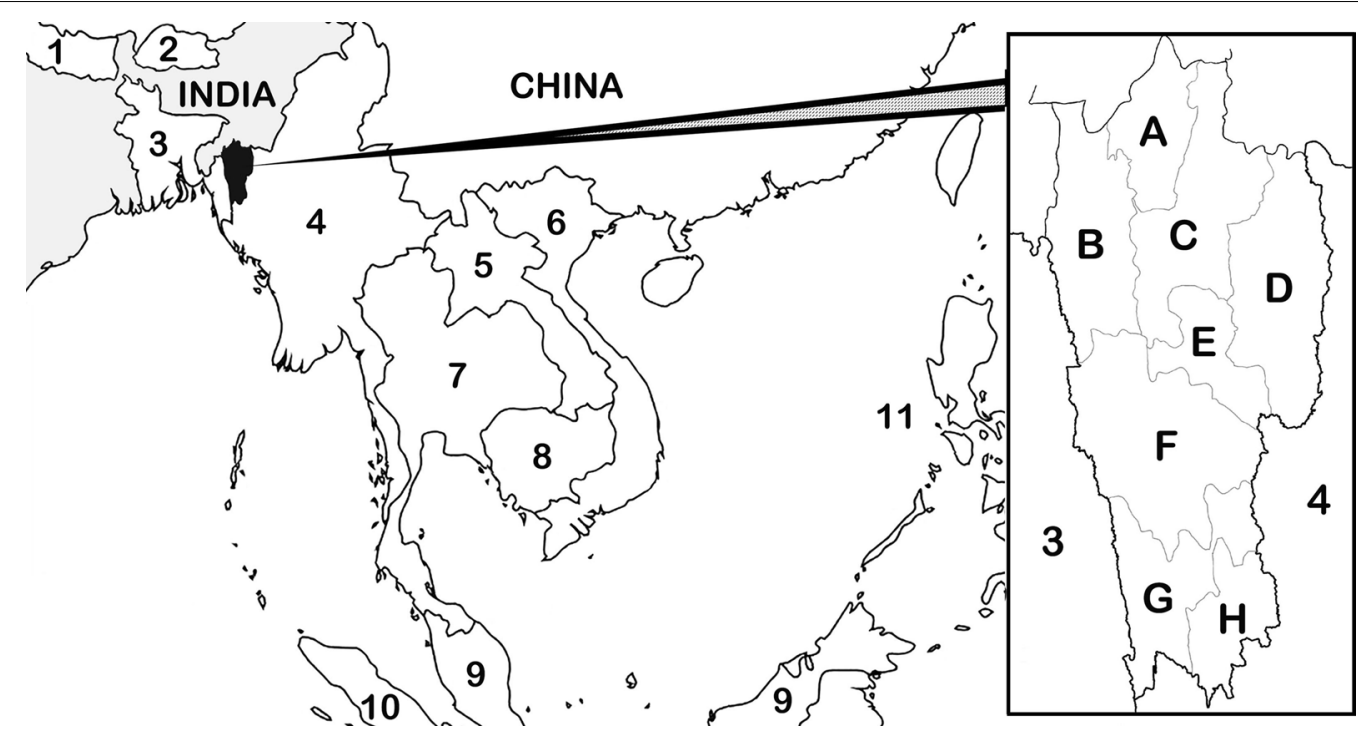

Fig. 1 Map of Mizoram, India illustrating its proximity to Southeast Asian countries. A Kolasib district, B Mamit district, C Aizawl district, D Champhai district, E Serchhip district, F Lunglei district, G Lawngtlai district, H Saiha district. 1 Nepal, 2 Bhutan, 3 Bangladesh, 4 Republic of the Union of Myanmar, 5 Laos, 6 Vietnam, 7 Thailand, 8 Cambodia, 9 Malaysia, 10 Indonesia, 11 Philippines

relapse infection, age and gender of the patient, date of blood examination and collection of samples; onset and duration of anti-malarial drug treatment administered were recorded for each blood sample collected. Blood samples were spotted on filter paper or were collected in EDTA vials, and preserved at $-20^{\circ} \mathrm{C}$ for further analysis.

\section{DNA extraction and species-specific identification of malaria parasite}

QIAamp Mini Kit (QIAGEN) was used to extract genomic DNA from positive $P$. falciparum samples according to manufacturer protocol. The extracted DNA was stored at $-20^{\circ} \mathrm{C}$ prior to use. Confirmatory PCR to detect $P$. falciparum and $P$. vivax was performed by targeting the 18SrRNA region as previously described [22].

\section{PCR amplification and sequencing}

The details used for $p f c r t$ and $p f m d r$ are given in Additional file 1: Table S1. For pfcrt, three nested PCRs were performed using gene-specific primers to detect polymorphism at exons $1-2,2-8$ and 9-12. The primary PCR was carried out in $25 \mu \mathrm{l}$ volume using EmeraldAmp GT PCR mix (Takara Bio Inc., Japan), $0.1 \mu \mathrm{M}$ primers and 1-3 $\mu$ l of DNA template. The PCR conditions were $94{ }^{\circ} \mathrm{C}$ for $5 \mathrm{~min}, 35$ cycles of $92{ }^{\circ} \mathrm{C}$ for $30 \mathrm{~s}, 50{ }^{\circ} \mathrm{C}$ for $40 \mathrm{~s}, 62^{\circ} \mathrm{C}$ for $1 \mathrm{~min}$ and a final extension at $62^{\circ} \mathrm{C}$ for $5 \mathrm{~min}$. For the nested PCR, the primary PCR product was diluted 10 times and $1 \mu \mathrm{l}$ was used as a template for $50 \mu \mathrm{L}$ reaction volume. The nested PCR conditions were $94^{\circ} \mathrm{C}$ for $4 \mathrm{~min}$, 35 cycles of $92^{\circ} \mathrm{C}$ for $1 \mathrm{~min}, 55^{\circ} \mathrm{C}$ for $40 \mathrm{~s}, 72^{\circ} \mathrm{C}$ for $1 \mathrm{~min}$ and a final extension step of $72{ }^{\circ} \mathrm{C}$ for $5 \mathrm{~min}$. The PCR products ( $40 \mu \mathrm{L}$ approx.) were purified from agarose gel using QIAquick Gel Extraction Kit (QIAGEN) according to manufacturer protocol and then immediately sent for sequencing. Pfmdr1 PCR was carried out in $25 \mu \mathrm{l}$ volume using EmeraldAmp GT PCR mix (Takara Bio Inc., Japan), $0.1 \mu \mathrm{M}$ primers and $1-3 \mu \mathrm{l}$ of DNA template. For amplifying codons 86 and 184, the PCR conditions were $94{ }^{\circ} \mathrm{C}$ for $5 \mathrm{~min}$, and 35 cycles of $94{ }^{\circ} \mathrm{C}$ for $30 \mathrm{~s}, 52{ }^{\circ} \mathrm{C}$ for $30 \mathrm{~s}$, $72{ }^{\circ} \mathrm{C}$ for $1 \mathrm{~min}$ and a final extension at $72{ }^{\circ} \mathrm{C}$ for $5 \mathrm{~min}$. For codons 1034, 1042 and 1246, the annealing temperature used was $56^{\circ} \mathrm{C}$ for $30 \mathrm{~s}$. The PCR products were preserved at $-20{ }^{\circ} \mathrm{C}$ prior to sequencing.

The PCR amplicons were sequenced at DBT- State Biotech Hub, Dept of Biotechnology, Mizoram University, Aizawl, Mizoram and Agrogenome, Cochin, Kerala, India.

\section{Data analysis \\ Epidemiological data}

The following parameters were calculated:- total blood examined (TBE $=$ total blood slides examined + total rapid diagnostic test (RTD) conducted; if an individual was tested for both blood slides and RTD, blood slide was considered), total blood positive for malaria (TBM=blood slides + RDT; both positive for malaria), surveillance coverage $(\mathrm{SC}=\mathrm{TBE} /$ overall fever cases $\times 100)$, annual blood examination rate $(\mathrm{ABER}=\mathrm{TBE} /$ population $\times 100)$, slide positive rate $(\mathrm{SPR}=\mathrm{TBM} / \mathrm{TBE} \times 100)$, per cent $P$. falciparum $(\%$ 
$\mathrm{Pf}=$ blood positive for $P$. falciparum $/ \mathrm{TBM} \times 100$ ), per cent $P$. vivax $(\% \mathrm{Pv}=$ blood positive for $P$. vivax $/ \mathrm{TBM}$ $\times 100)$.

\section{Nucleotide and amino acid data}

The pfcrt and pfmdr1 nucleotide and amino acid sequences were aligned using MAFFT [23] and MEGA 7 [24]. The pfcrt sequences were aligned with 3D7 CQS strain (GenBank Accession No. AL844506.3:403222406317) to detect polymorphisms at 11 codon positions: 72 (C/S), $74(\mathrm{M} / \mathrm{I}), 75$ (N/E), 76 (K/T), 152 (T/A), 163 (S/R), 220 (A/S), 271 (Q/E), $326(\mathrm{~N} / \mathrm{S}), 356$ (I/T) and 371 (R/I). Pfmdr1 sequences were aligned with the reference 3D7 sequence (GenBank Acc. No. NC 004326:957885962144), and were analysed for point mutations at positions $86(\mathrm{~N} / \mathrm{Y}), 184(\mathrm{Y} / \mathrm{F}), 1034(\mathrm{~S} / \mathrm{C}), 1042(\mathrm{~N} / \mathrm{D})$ and $1246(\mathrm{D} / \mathrm{Y})$.

\section{Statistical analysis}

Epidemiological and molecular data were entered, analysed in Excel (Microsoft) and graphical presentations were also performed in Excel. Association between pfcrt and pfmdr1 mutation was analysed using Chi square test in Statistical Package for Social Science (IBM SPSS Statistics for Windows, Version 24.0. IBM Corp., Armonk, NY, USA).

\section{Results}

\section{Malaria epidemiology analysis}

Malaria epidemiology recorded during 2010-2018 showed that malaria was persistent throughout the year, and across all districts in the state. The surveillance coverage accounted for $\geq 95 \%$ in all sites of study (Fig. 2). Majority of malarial infection and malaria-related death was due to $P$. falciparum infection and accounted for 89.3\% of total malaria cases (Fig. 2 and Additional file 3: Table S3). The observed highest malaria incidence and malaria-related deaths was in 2014. Reason for the high mortality rate in 2014 was because the majority of infection had evolved to hyper-reactive malarial splenomegaly. The factors were: (i) lack of timely detection of the parasite due to lack of transportation (mainly roadblock due to landslides); and, (ii) less availability of $P$. falciparum treatment (ACT-AL) in almost all rural medical facilities; patients were devoid of immediate medical assistance. However, a decline in the number of malariarelated deaths was observed in subsequent years (Fig. 2). The total number of death due to malaria was 172; Mamit and Lawngtlai recorded deaths annually throughout the study period (Additional file 3: Table S3).

Overall, most malaria incidence was contributed by Lawngtlai (average $\mathrm{API}_{2010-2018}=34.8$; total number of malaria cases $=41,516$; number of $P$. falciparum $=37,892$;

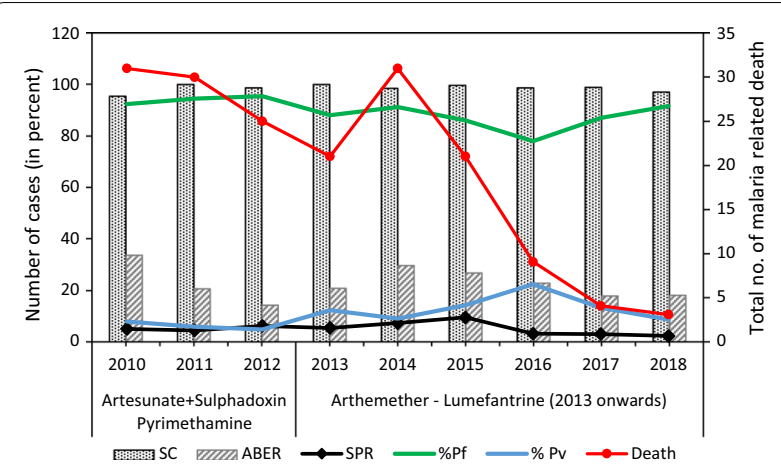

Fig. 2 Overall summary of malaria epidemiology for 9 years (2010-2018) highlighting malaria-related deaths and the treatment used for Plasmodium falciparum cases. SC surveillance coverage, ABER annual blood examination rate, SPR slide positive rate, \%Pf per cent of blood positive for P. falciparum, \%Pv per cent of blood positive for $P$. vivax. (The calculations for these parameters are explained in the "Methods" section)

number of $P$. vivax $=3664$ ); followed by Mamit (average $\mathrm{API}_{2010-2018}=34.4$; total malaria cases $=23,391 ; P$. falciparum $=21,497 ; P$. vivax $=1894)$. The total sum of malaria cases (total malaria, total P. falciparum, $P$. vivax infections and death) throughout 9 years of study was calculated. This was an attempt to observe the trend of infection and to find any discrepancy in its abundance at monthly resolution (Fig. 3). A consistent and cyclic pattern of gradual increase in malaria cases during the rainy summer/monsoon season (March to September) was observed. The cases peaked in June to July and then decreased during the dry winter season (October to January) (Fig. 3). A similar pattern was also observed for the number of malaria-related deaths in all study areas, excluding Mamit and Lawngtlai. Maximum deaths were reported from Mamit $(n=13)$ during August.

Distribution of age and gender-specific malarial infection, passive case detection and pregnancy infections recorded for 2014 to 2018 were analysed (Table 1). Overall, 15+years of age had the highest malaria incidence $(39,407 / 69,178)$, whereas $\leq 4$ years of age had the lowest $(9047 / 69,178)$. Males of $15+$ years contributed the highest with $35.9 \%$ of total cases (Table 1, Additional file 3: Table S3). The total number of pregnancy infections recorded from 2014 to 2018 was 364 ( $0.53 \%$ total malaria cases), and deaths during pregnancy were not reported. A total of 61,501 individuals were recorded for passive case detection (PCD).

\section{Molecular analysis of pfcrt and pfmdr 1 for CQR mutation} Previously characterized $p f c r t$ mutations in 11 amino acid loci 73-76, 152 and 163, 220, 271, 326, 356 and 371 conferring CQR were analysed in 265 P. falciparum-infected 

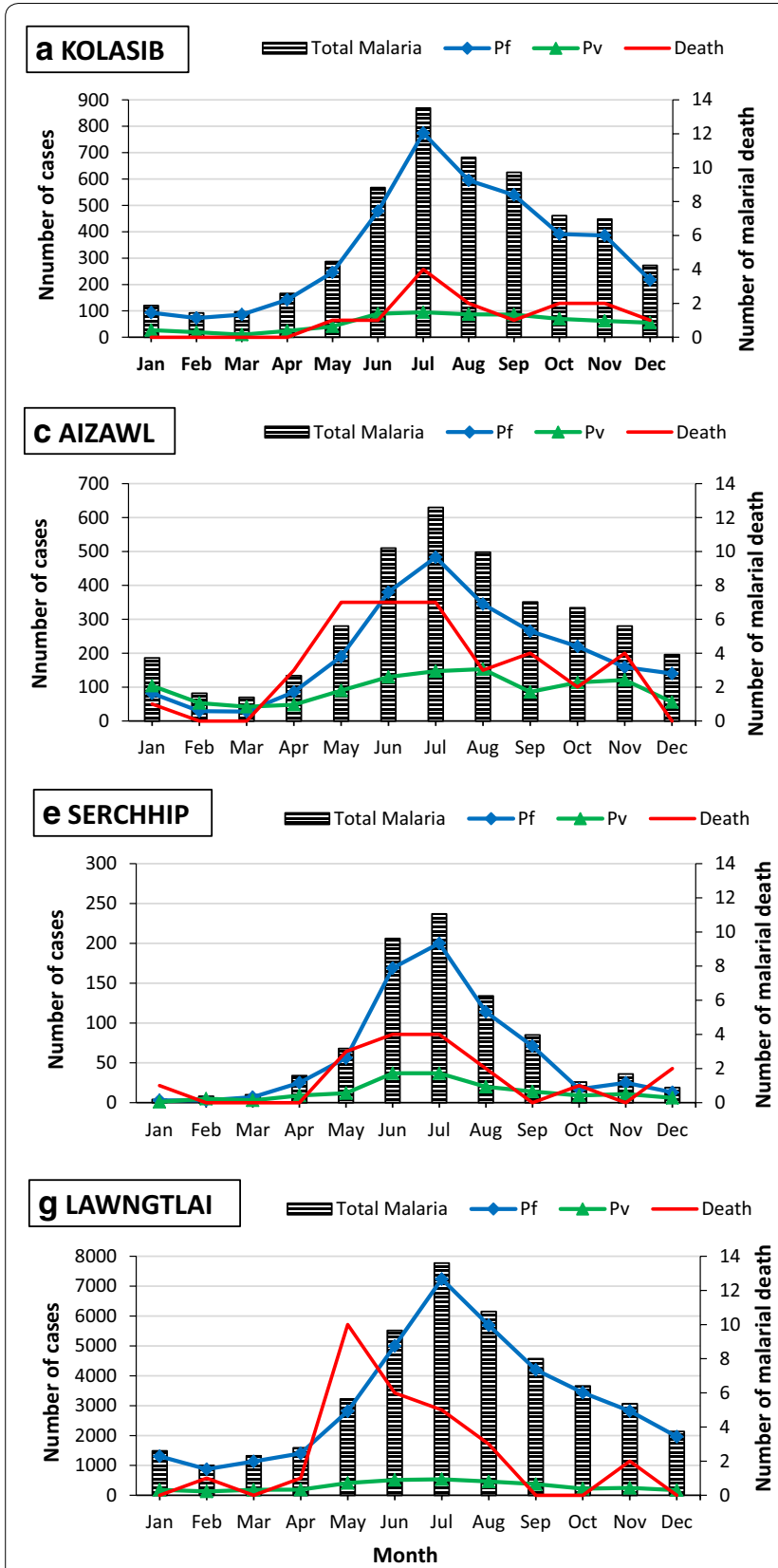
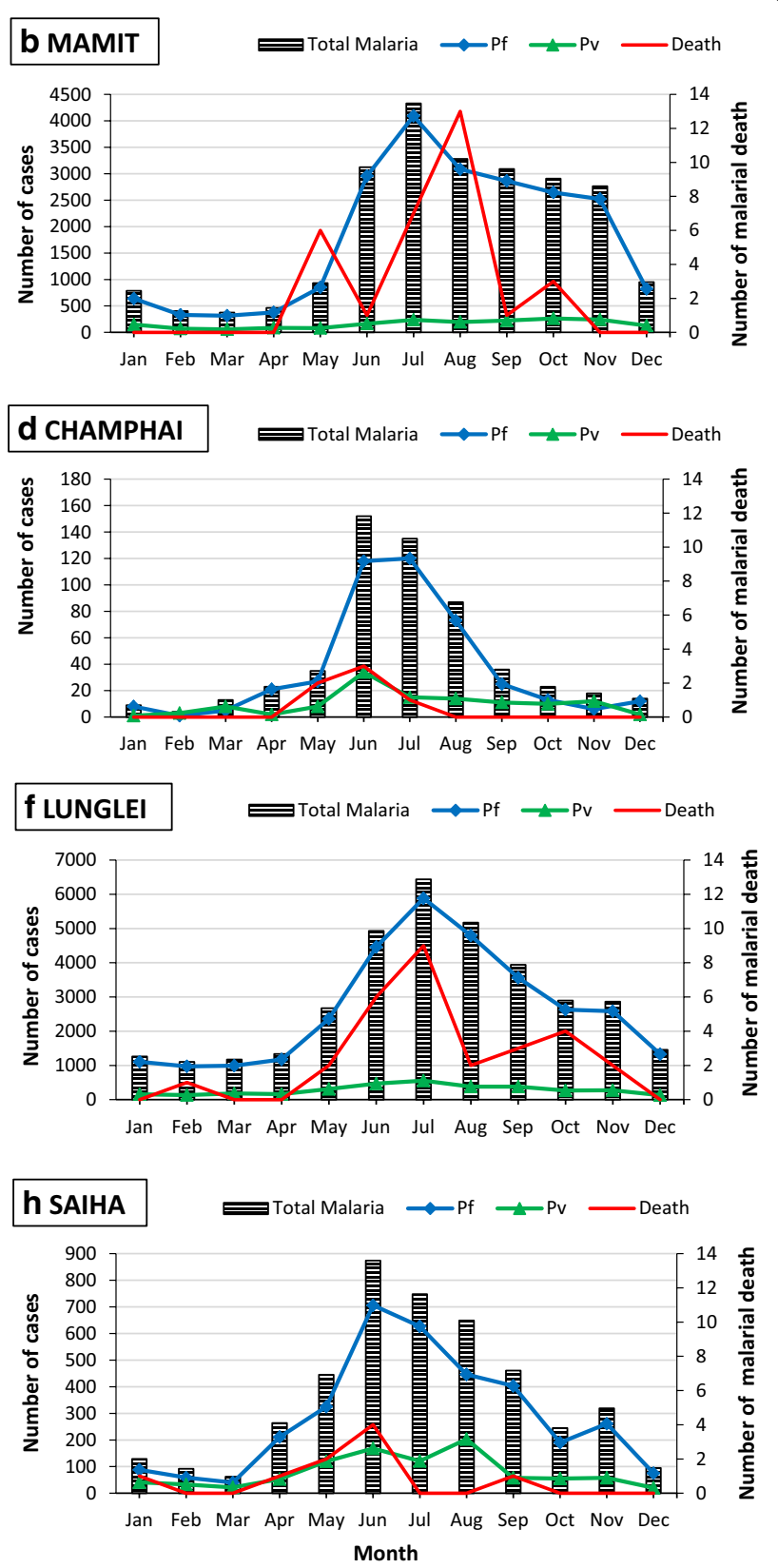

Fig. 3 Monthly distribution of malaria cases and malaria-related deaths (2010-2018) at each study site (a-h)

clinical blood samples from 2015 to 2017. 3D7 strain was used as a reference. Some $41.5 \%(110 / 265)$ of the samples displayed sequence similarity with the reference sequence, and were denoted as 'WT' (wild type). The remaining $58.5 \%(155 / 265)$ of the samples displayed substitutions at 7 amino acid positions (CQR mutations) and were distributed throughout the study sites (Table 2). These samples are denoted as 'R'. All the R samples were positive for the Southeast Asian CVIET pfcrtresistant haplotype. Within the $\mathrm{R}$ populations, because of additional amino acid polymorphism at positions 220 $(\mathrm{A} \rightarrow \mathrm{S}), 271(\mathrm{Q} \rightarrow \mathrm{E})$ and $371(\mathrm{R} \rightarrow \mathrm{I})$, a further subdivision was made into 'R1' (IET-AQ-S-R) and 'R2' (IET-SES-I) (Table 2). R1 and R2 constituted 48.4 and $51.6 \%$ of the total CQR mutated populations, respectively. The distribution of WT and R (R1 and R2) among the 7 districts of Mizoram is given in Fig. 4. WT, R1 and R2 were not uniformly distributed within Mizoram; WT was observed highest in Aizawl with $75 \%$ of the total sample analysed $(26 / 35)$, followed by Kolasib $(62 \%, 18 / 29)$ and Saiha $(61 \%$, 


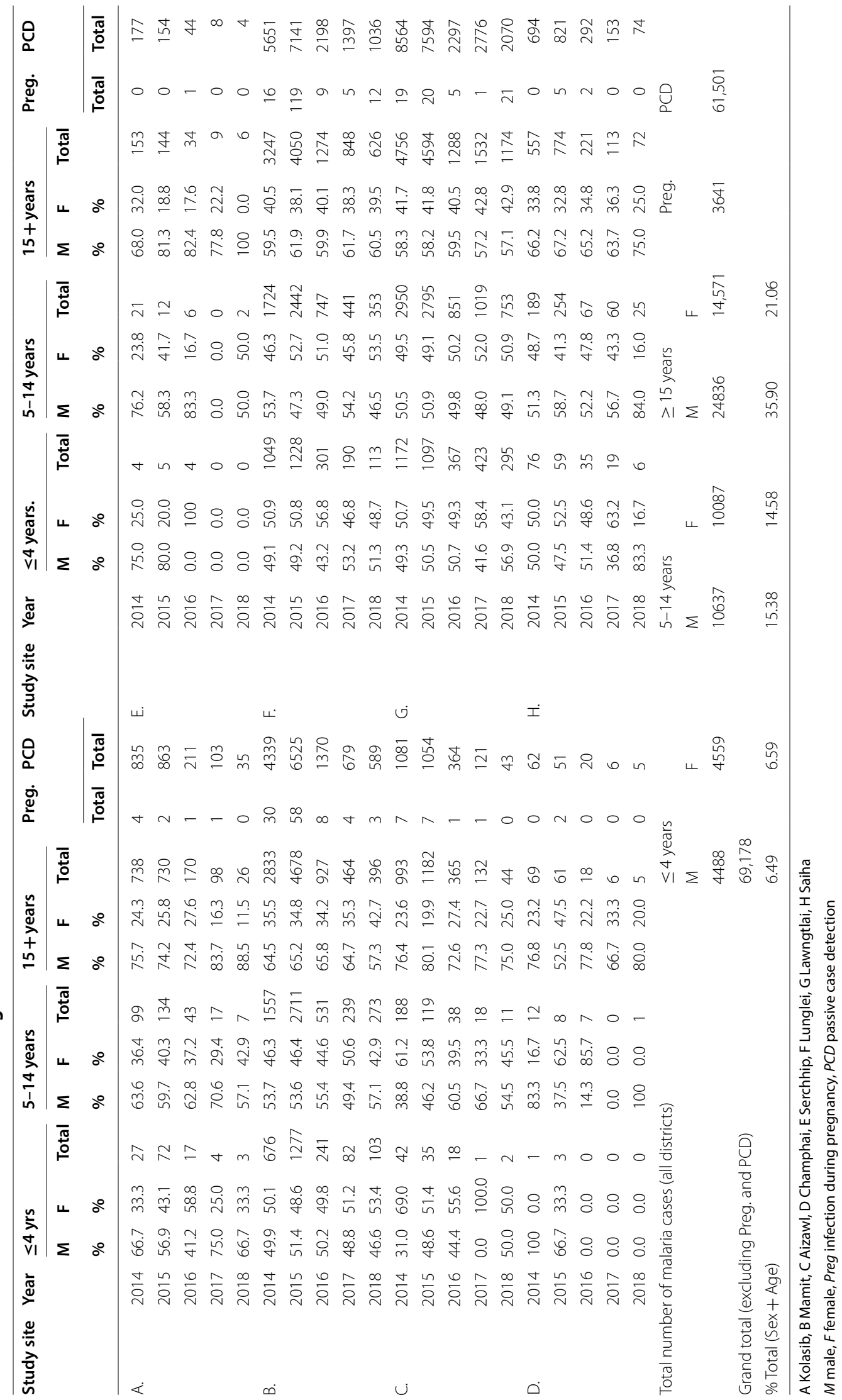


Table 2 Pattern of pfcrt amino acid sequence diversity of at seven amino acid positions

\begin{tabular}{|c|c|c|c|c|c|c|c|c|}
\hline \multicolumn{2}{|l|}{ Exon number } & \multirow{3}{*}{$\begin{array}{l}2 \\
74 \\
M / I(\%)\end{array}$} & \multirow{3}{*}{$\begin{array}{l}2 \\
75 \\
\text { N/E (\%) }\end{array}$} & \multirow{3}{*}{$\begin{array}{l}2 \\
76 \\
\text { K/T (\%) }\end{array}$} & \multirow{3}{*}{$\begin{array}{l}4 \\
220 \\
\text { A/S (\%) }\end{array}$} & \multirow{3}{*}{$\begin{array}{l}6 \\
271 \\
\text { Q/E (\%) }\end{array}$} & \multirow{3}{*}{$\begin{array}{l}9 \\
326 \\
\text { N/S (\%) }\end{array}$} & \multirow{3}{*}{$\begin{array}{l}11 \\
371 \\
\text { R/I (\%) }\end{array}$} \\
\hline Amino acid loci and sub & Ition & & & & & & & \\
\hline Study sites & $N(n R)$ & & & & & & & \\
\hline \multirow[t]{2}{*}{ A. Kolasib } & 29 & $M(62.1)$ & $N(62.1)$ & K (62.1) & $A(86.2)$ & Q (86.2) & $N(62.1)$ & R (86.2) \\
\hline & $(11)$ & I (37.9) & $E(37.9)$ & $\mathrm{T}(37.9)$ & $S(13.8)$ & $E(13.8)$ & $S(37.9)$ & I (13.8) \\
\hline \multirow[t]{2}{*}{ B Mamit } & 35 & $M(40.0)$ & N (40.0) & $K(40.0)$ & $A(62.9)$ & $Q(62.9)$ & $N(40.0)$ & $\mathrm{R}(62.9)$ \\
\hline & $(21)$ & I (60.0) & $E(60.0)$ & $\mathrm{T}(60.0)$ & $S(37.1)$ & $E(37.1)$ & $S(60.0)$ & I (37.1) \\
\hline \multirow[t]{2}{*}{ C. Aizawl } & 36 & $M(75.0)$ & $N(75.0)$ & $K(75.0)$ & $A(100)$ & $Q(100)$ & $N(75.0)$ & $R(100)$ \\
\hline & (9) & | (25.0) & $E(25.0)$ & $\mathrm{T}(25.0)$ & & & $S(25.0)$ & \\
\hline \multirow[t]{2}{*}{ E. Serchhip } & 21 & $M(47.6)$ & N (47.6) & K (47.6) & $A(100)$ & $Q(100)$ & $N(47.6)$ & $R(100)$ \\
\hline & $(11)$ & I (52.4) & E (52.4) & $\mathrm{T}(52.4)$ & & & S (52.4) & \\
\hline \multirow[t]{2}{*}{ F. Lunglei } & 61 & $M(21.3)$ & $N(21.3)$ & K (21.3) & $A(52.5)$ & $Q(52.5)$ & S (78.7) & $R(52.5)$ \\
\hline & $(48)$ & I (78.7) & $E(78.7)$ & $\mathrm{T}(78.7)$ & $S(47.5)$ & $E(47.5)$ & $\mathrm{N}(21.3)$ & I (47.5) \\
\hline \multirow[t]{2}{*}{ G. Lawngtlai } & 57 & $M(21.1)$ & $\mathrm{N}(21.1)$ & K (21.1) & A (47.4) & $\mathrm{Q}(47.4)$ & $\mathrm{N}(21.1)$ & $R(47.4)$ \\
\hline & $(45)$ & I (78.9) & E (78.9) & $\mathrm{T}(78.9)$ & $S(52.6)$ & $E(52.6)$ & S (78.9) & I (52.6) \\
\hline \multirow[t]{2}{*}{ H. Saiha } & 26 & M (61.5) & $N(61.5)$ & K (61.5) & A (84.6) & Q (84.6) & $\mathrm{N}(61.5)$ & R (84.6) \\
\hline & (10) & I (38.5) & $E(38.5)$ & $\mathrm{T}(38.5)$ & S (15.4) & $E(15.4)$ & S (38.5) & I (15.4) \\
\hline 3D7 Reference sequence & & M & $\mathrm{N}$ & K & A & Q & $\mathrm{N}$ & $\mathrm{R}$ \\
\hline \multicolumn{9}{|l|}{ Genotypes } \\
\hline 1. WT & & $M$ & $\mathrm{~N}$ & K & A & Q & $\mathrm{N}$ & $\mathrm{R}$ \\
\hline 2. R1 & & I & E & $\mathrm{T}$ & A & Q & $\mathrm{S}$ & $\mathrm{R}$ \\
\hline 3. $\mathrm{R} 2$ & & 1 & E & $\mathrm{T}$ & $S^{a}$ & $E^{a}$ & $\mathrm{~S}$ & $1^{a}$ \\
\hline
\end{tabular}

$n$ total number of samples, $n R$ number of samples with $\mathrm{R}$ forms, WT wild type, $R 1$ CQR type-1, R2 CQR type-2

a Denotes additional substitutions; All calculations are in percentage

16/26). Lawngtlai, Lunglei and Mamit showed a higher prevalence of R forms; 78.9\% (45/57), 78.7\% (48/59) and $60 \%(21 / 35)$, respectively (Fig. 4). Within R populations, Aizawl and Serchhip were positive only for R1; mixed populations of R1 and R2 were observed in Lunglei, Saiha, Kolasib, and Lawngtlai. R2 was highest in Lawngtlai (52\%) followed by Lunglei (47.5\%) (Fig. 4). All the $p f c r t$ nucleotide sequences were deposited to GenBank (see Additional file 2: Table S2).

A total of 356 samples were sequenced and all nucleotide sequences were deposited to GenBank (see Additional file 2: Table S2). Table 3 shows the analysis of pfmdr1 mutations obtained from these study areas. Analysis for mutation at amino acid 86 position showed that 174 samples (48.9\% of the total sample) displayed the N86Y mutation (Table 3). However, amino acid sequences displayed no polymorphisms at $184(\mathrm{Y} / \mathrm{F})$, $1034(\mathrm{~S} / \mathrm{C}), 1042(\mathrm{~N} / \mathrm{D})$ and $1246(\mathrm{D} / \mathrm{Y})$. The highest (63.2\%) and lowest (28.6\%) number of N86Y mutations were observed in samples from Lunglei and Aizawl, respectively. Lawngtlai showed uniform distribution of N86 and 86Y (Table 3).

The result of Chi square analysis in 265 samples tested for both pfcrt and pfmdr1 polymorphisms showed a significant association existed between the mutations $\left(\mathrm{x}^{2}=121.48, \mathrm{df}=1, \mathrm{p}=0.001, \phi_{\mathrm{c}}=0.68\right)$. The key $86 \mathrm{Y}$ mutation in pfmdr1 that had been shown to modulate CQR was found in $67.1 \%$ of R-population of pfcrt gene $(\mathrm{n}=155)$ analysed, meanwhile its mutation was found to be nil in WT-populations of $p f c r t(n=110)$ (Fig. 4).

\section{Discussion}

Historically the spread of CQR has been linked from SEA to Africa via the Indian subcontinent $[25,26]$, and NE states could have contributed to CQR spread in mainland India through host movements [7]. The eastern region of Mizoram shares its international border with Myanmar. By land, one can enter Tedim in the Chin state of Myanmar through the Zokhawthar-Rih border of Champhai district. Both regions share a historical similarity in ethnic, religion, culture, and language [27]. Trade relations between the locals in the border areas have led to continuous movement of people in both directions. Despite the strategic location of Mizoram, and its importance as a conduit for the spread of drug-resistant $P$. falciparum, malaria epidemiology and drug resistance status have been poorly documented.

This is the first study to give a detailed account of malaria epidemiology in Mizoram in this decade. Plasmodium falciparum contributes to the majority of the 


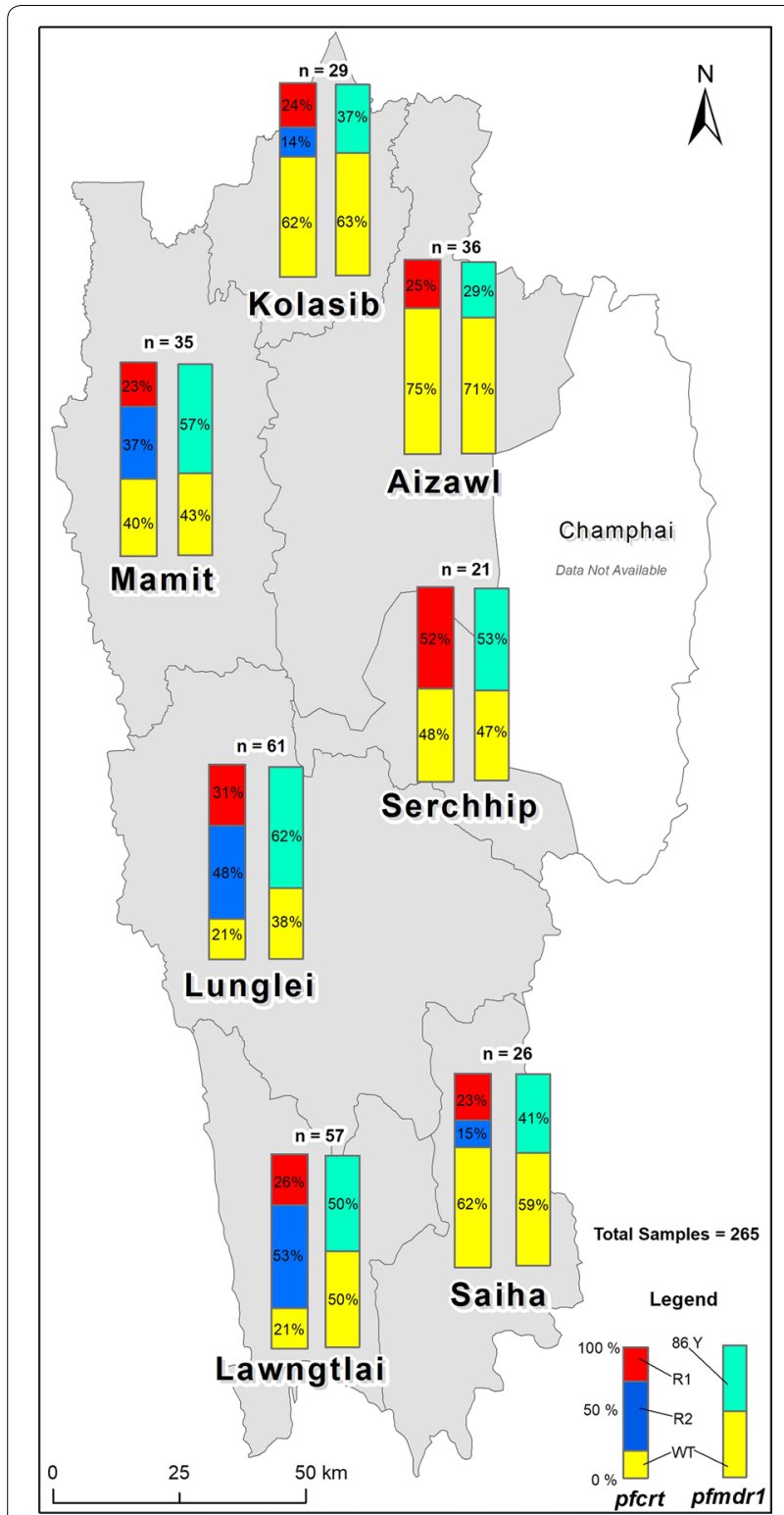

Fig. 4 Distribution of chloroquine resistance transporter ( $p f c r t$ ) and multidrug-resistant ( $p f m d r 1$ ) genotypes across Mizoram. WT wild type, R CQR genotype, R1 CQR type-1, R2 CQR type-2; 86Y:

$\mathrm{N} \rightarrow \mathrm{Y}$ substitution at 86 amino acid of $p$ fmdr 1 ; All calculations are in percentages

cases (> 89\%) in Mizoram, similar to that observed in its national borders [1]. A study carried out in the early $1980 \mathrm{~s}$ incriminated Anopheles minimus and Anopheles dirus as the major vectors in Mizoram [28, 29]. Additionally, recent studies on vector distribution identified Anopheles campestris, Anopheles jeyporiensis, Anopheles maculatus, and Anopheles nivipes as the most abundant species in malaria endemic parts of Mizoram [30, 31]. It has also been documented that the rise in Anopheles populations is subsequently followed by a peak in malaria cases [31]. In all districts of Mizoram, malaria cases peak during the major monsoon season: May to July (Fig. 3). Malaria transmission is perennial and cases are reported throughout the year; the burden is highest in the districts of Lunglei, Lawngtlai and Mamit. Champhai, which links with Myanmar through an international highway, consistently reported the least API score (Additional file 3: Table S3). The low parasite prevalence could be attributed to its high elevation (1678 $\mathrm{m}$ above sea level), in parallel with low abundance of anopheline species in the region. Even though Mizoram is a high malaria-endemic region, a gradual decrease in the number of $P$. falciparum cases and mortality due to malaria has been observed from 2010 onwards. One important factor could be attributed to the current $P$. falciparum treatment (ACT-AL), and to the strategies implemented by the SVDCP that includes: visual and verbal awareness campaigns about the disease, and about potential breeding habitats, outdoor residual spraying of DDT twice a year, and quinquennial distribution of $>500,000$ deltamethrin-treated bed nets. This is evidenced by the substantial number of PCD seeking medical care (Table 1). Furthermore, efficient and easy access to healthcare facilities could contribute to effective management and timely treatment of pregnancy infections as not a single pregnancy death due to malaria has been reported during the study.

This is the first report conducted to determine the molecular status of CQR in Mizoram; the study targeted the established molecular markers of $p f c r t$ and pfmdr1. Artesunate + SP is currently the treatment for uncomplicated P. falciparum in all parts of India, except NE India. It has been a decade since the use of CQ for P. falciparum cases; the change from CQ to ACT-AL as first-line treatment was expected to result in wide spread distribution of CQS allele within the P. falciparum population, as documented in many African countries [32-36]. Unexpectedly, only $41.5 \%(110 / 265)$ of the samples were identified as CQS type in the study sites (Fig. 4). Perhaps this is because CQ (the current the treatment for P. vivax infection) could be employed for treating unrecognized mixed infections, thereby making $P$. falciparum vulnerable to the drug [37]. In addition, the present study on pfcrt polymorphisms indicated that CQS (41.5\%) and CQR (58.5\%) co-existed, albeit when CQ treatment ceased, in a manner similar to other parts of Asia [38, 39] (Fig. 4). In India, the major pfcrt haplotype identified is the SVMNT; yet, varying frequencies of CVIET, CVIDT and CVMNT have also been reported [40-44]. Interestingly, in Mizoram was observed with 58.5\% (155/265) of the samples were positive for CVIET allele, and is the only haplotype available in the region; CVIET is the predominant CQR-allele found mainly in SEA. The P. falciparum 
Table 3 Analysis of pfmdr 1

\begin{tabular}{|c|c|c|c|c|c|c|}
\hline Study sites & $N$ & N86Y (\%) & Y184F (\%) & S1034C (\%) & N1042D (\%) & D1246Y (\%) \\
\hline Kolasib & 32 & $N(63.6) ; Y(36.4)$ & Y184 (100) & S1034 (100) & N1042 (100) & $\mathrm{D} 1246(100)$ \\
\hline Mamit & 44 & $N(43.5) ; Y(56.5)$ & & & & \\
\hline Aizawl & 42 & $N(71.4) ; Y(28.6)$ & & & & \\
\hline Serchhip & 86 & $N(46.7), Y(53.3)$ & & & & \\
\hline Lunglei & 74 & $N(36.8) ; Y(63.2)$ & & & & \\
\hline Lawngtlai & 46 & $N(50.0), Y(50.0)$ & & & & \\
\hline Saiha & 32 & $N(59.4) ; Y(40.6)$ & & & & \\
\hline
\end{tabular}

$N$ number of samples analysed. (All calculations are in percentage)

population, having the CVIET allele was further divided into two groups: R1 (CVIET-AQ-S-R) and R2 (CVIETSE-S-I); R2 contains amino acid substitutions similar to Old World-resistant phenotype [45, 46] (Table 2). Subsequent in vitro studies on R1 and R2 of local P. falciparum populations may give rise to further prospective study on CQ-sensitivity in the future.

Globally, five-point mutations (N86Y, Y184F, S1034C, N1042D and D1046) have been described for $p f m d r 1$ and, importantly, $86 \mathrm{Y}$ polymorphism is linked with decreased sensitivity to CQ [47] and amodiaquine (chemically similar to CQ) $[48,49]$. It has been recorded that the $\mathrm{N}$ terminal, N86Y and Y184F mutations are more prevalent in African and Asian parasites, while the $\mathrm{C}$ terminal mutations: S1034C, N1042D and D1046Y are more common in South American parasites [15]. This study identified a single $86 \mathrm{Y}$ substitution at the $\mathrm{N}$ terminal region with $48.9 \%(174 / 356)$ while the remaining $51.1 \%(182 / 356)$ displayed uniformity throughout the amino acid sequence. Substitutions at 184 and the later three codon positions discussed above were not observed. Analysis indicates that $67.1 \%$ of samples with CVIET haplotype also carried N86Y mutation. A similar pattern had been observed in parts of India [37], Asia [38, 50-52] and Africa [35, 53, 54].

\section{Conclusion}

Malaria is perennial throughout Mizoram and P. falciparum transmission accounts for more malaria cases than P. vivax. However, the efforts of SVDCP have proved to be quite effective in controlling the malaria burden in the state, reducing malaria transmission and malaria deaths over the years. The only available CQR allele found across the state is the South Asian CVIET haplotype. Despite the discontinuance of $\mathrm{CQ}$ for a decade, polymorphisms at $p f c r t(76 \mathrm{~T})$ and $p f m d r 1$ (86Y) continued to exist at an unexpected rate. In addition, a single polymorphism at site 86 of $p f m d r 1$ proved to be a unique characteristic feature of local resistant $P$. falciparum population. It is speculated that less abundance of mutated pfmdr 186
$(\mathrm{N} \rightarrow \mathrm{Y})$ substitution and absence of polymorphism at codon 184, 1034, 1042 and 1046 loci may still contribute to high efficacy in artemisinin-lumefantrine treatment currently employed within the region. Further studies on genetic diversity of local $P$. falciparum in greater detail would confer better understanding about the complexity of the disease.

\section{Supplementary information}

Supplementary information accompanies this paper at https://doi. org/10.1186/s12936-020-03170-3.

Additional file 1: Table S1. Details of primers used in the study.

Additional file 2: Table S2. Voucher ID of samples and their respective GenBank Accession Numbers.

Additional file 3: Table S3. . Detailed analysis on epidemiological data.

\section{Abbreviations}

Pfcrt: P. falciparum chloroquine resistant transporter; pfmdr1: P. falciparum multidrug resistance 1; SEA: Southeast Asia; NE: North East India; SVDCP: State Vector Disease Control Programme; NVBDCP: National Vector Borne Disease Control Programme; CQ: Chloroquine; CQR: Chloroquine resistance; SP: Sulfadoxine-pyrimethamine; ACT: Artemisinin-based combination therapy; AL: Artemether-lumefantrine.

\section{Acknowledgements}

The authors would like to thank all P. falciparum patients for their willingness to participate in the study. We would also like to thank the coordinators of Institutional Biotech Hub, Pachhunga University College and DBT, New Delhi sponsored_Advanced Biotech Hub, Mizoram University for providing infrastructural facilities during the study period. The authors also thank $\mathrm{K}$ Balasubramani, Dept of Geography, Central University of Tamil Nadu, for his help in graphical presentations.

\section{Authors' contributions}

All authors contributed to study design and data analysis. RZ and NSK undertook laboratory work. RZ and LP collected epidemiological data. RZ, PBN, and NSK drafted the manuscript; and $\mathrm{CLH}$ and $\mathrm{KL}$ contributed medical supervision and discussion of the manuscript. All authors read and approved the final manuscript.

\section{Funding}

This work was supported by the Women Scientist-A scheme, Dept. of Science \& Technology, Govt. of India (File No. SR/WOS-A/LS-1205/2014 (G) dt. 01.07.2015). 


\section{Availability of data and materials}

The datasets during and/or analysed during the current study available from the corresponding author on reasonable request.

\section{Ethics approval and consent to participate}

Ethical approval was obtained from the Institutional Human Ethics Committee, Mizoram University, Aizawl, for laboratory work in Mizoram (No. MZU/ IHEC/2019/005). Samples were collected after getting consent from the patients (and guardians) and for patients less than 10 years of age, consent was obtained from their guardians (parents).

\section{Consent for publication}

Not applicable.

\section{Competing interests}

The authors declare that they have no competing interests.

\section{Author details}

${ }^{1}$ Department of Biotechnology, Mizoram University, Aizawl, Mizoram, India. 2 Department of Orthopaedics, District Hospital, Government of Mizoram, Serchhip, Aizawl, Mizoram, India. ${ }^{3}$ Department of Medicine, District Hospital, Government of Mizoram, Serchhip, Aizawl, Mizoram, India. ${ }^{4}$ State Vector Disease Control Programme, Department of Health and Family Welfare, Government of Mizoram, Aizawl, Mizoram, India. ${ }^{5}$ Department of Epidemiology and Public Health, Central University of Tamil Nadu, Tiruvarur, Tamil Nadu, India.

Received: 29 September 2019 Accepted: 17 February 2020

Published online: 27 February 2020

\section{References}

1. WHO. World malaria report 2018. Geneva, World Health Organization, 2018. https://apps.who.int/iris/handle/10665/275867.

2. Dhiman $S$, Veer V, Dev V. Declining transmission of malaria in India: accelerating towards elimination. In: Manguin S, Dev V, editors. Towards malaria elimination. London: In TechOpen; 2018. p. 251-306. https://doi. org/10.5772/intechopen.77046.

3. National Vector Borne Disease Control Programme. Malaria situation from 2015. 2018. https://nvbdcp.gov.in/WriteReadData//892s/1504833116 1580734250.pdf. Accessed 09 Sept 2019.

4. Dikshit KR, Dikshit JK. Weather and climate of North-East India. North-East India: land, people and economy. Springer: Netherlands; 2014. p. 149-73. ISBN 978-94-007-7054-6.

5. Sehgal PN, Sharma MID, Sharma SL, Gogoi S. Resistance to chloroquine in falciparum malaria in Assam state, India. J Commun Dis. 1973;5:175-80.

6. Barkakaty BN, Narasimham MV. Problem of antimalarial drug resistance in Plasmodium falciparum in Mizoram. Indian J Malariol. 1992;29:89-93.

7. Shah NK, Dhillon GP, Dash AP, Arora U, Meshnick SR, Valecha N. Antimalarial drug resistance of Plasmodium falciparum in India: changes over time and space. Lancet Infect Dis. 2011;1:57-64.

8. Mohapatra PK, Prakash A, Taison K, Negmu K, Gohain AC, Namchoom NS, et al. Evaluation of chloroquine (CQ) and sulphadoxine/pyrimethamine (SP) therapy in uncomplicated falciparum malaria in Indo-Myanmar border areas. Trop Med Int Health. 2005;10:478-83.

9. Mishra N, Kaitholia K, Srivastava B, Shah NK, Narayan JP, Dev V, et al. Declining efficacy of artesunate plus sulfadoxine-pyrimethamine in northeastern India. Malar J. 2014;13:284.

10. Mohapatra PK, Sarma DK, Prakash A, Bora K, Ahmed MA, Sarma B, et al. Molecular evidence of increased resistance to anti-folate drugs in Plasmodium falciparum in North-East India: a signal for potential failure of artemisinin plus sulfadoxine-pyrimethamine combination therapy. PLoS ONE. 2014;9:e105562.

11. National Vector Borne Disease Control Programmme. National drug policy on malaria. 2013. [https://www.nvbdcp.gov.in/Doc/National-DrugPolicy-2013.pdf].

12. Alifrangis M, Dalgaard MB, Lusingu JP, Vestergaard LS, Staalsoe T, Jensen AT, et al. Occurrence of the Southeast Asian/South American SVMNT haplotype of the chloroquine-resistance transporter gene in Plasmodium falciparum in Tanzania. J Infect Dis. 2006;193:1738-41.
13. Djimde A, Doumbo OK, Cortese JF, Kayentao K, Doumbo S, Diourte $Y$, et al. A molecular marker for chloroquine-resistant falciparum malaria. N Engl J Med. 2001;344:257-63.

14. Srimuang K, Miotto O, Lim P, Fairhurst RM, Kwiatkowski DP, Woodrow CJ, et al. Analysis of anti-malarial resistance markers in mdr1 and crt across Southeast Asia in the tracking resistance to Artemisinin Collaboration. Malar J. 2016;15:541.

15. Ibraheem ZO, Abd Majid R, Noor SM, Sedik HM, Basir R. Role of different Crt and Pfmdr-1 mutations in conferring resistance to antimalaria drugs in Plasmodium falciparum. Malar Res Treat. 2014;2014:950424.

16. Huaman MC, Roncal N, Nakazawa S, Long TT, Gerena L, Garcia C, et al. Polymorphism of the Plasmodium falciparum multidrug resistance and chloroquine resistance transporter genes and in vitro susceptibility to aminoquinolines in isolates from the Peruvian Amazon. Am J Trop Med Hyg. 2004;70:461-6.

17. Vieira PP, Ferreira MU, Alecrim MD, Alecrim WD, da Silva LH, Sihuincha MM, et al. pfcrt polymorphism and the spread of chloroquine resistance in Plasmodium falciparum populations across the Amazon Basin. J Infect Dis. 2004;190:417-24.

18. Basco LK, Ringwald P. Analysis of the key pfcrt point mutation and in vitro and in vivo response to chloroquine in Yaounde, Cameroon. J Infect Dis. 2001;183:1828-31.

19. Antony HA, Das S, Parija SC, Padhi S. Sequence analysis of pfcrt and pfmdr1 genes and its association with chloroquine resistance in Southeast Indian Plasmodium falciparum isolates. Genomics Data. 2016;8:85-90

20. Sekihara M, Tachibana SI, Yamauchi M, Yatsushiro S, Tiwara S, Fukuda N, et al. Lack of significant recovery of chloroquine sensitivity in Plasmodium falciparum parasites following discontinuance of chloroquine use in Papua New Guinea. Malar J. 2018;17:434.

21. Gupta H, Macete E, Bulo H, Salvador C, Warsame M, Carvalho E, et al. Drug-resistant polymorphisms and copy numbers in Plasmodium falciparum, Mozambique, 2015. Emerg Infect Dis. 2018;24:40-8.

22. Snounou G, Viriyakosol S, Zhu XP, Jarra W, Pinheiro L, do Rosario VE, et al. High sensitivity of detection of human malaria parasites by the use of nested polymerase chain reaction. Mol Biochem Parasitol. 1993;61:315-20.

23. Katoh K, Standley DM. MAFFT multiple sequence alignment software version 7: improvements in performance and usability. Mol Biol Evol. 2013;30:772-80.

24. Kumar S, Stecher G, Tamura K. Molecular evolutionary genetics analysis Version 7.0 for bigger datasets. Mol Biol Evol. 2016;33:1870-4.

25. Su X, Kirkman LA, Fujioka H, Wellems TE. Complex polymorphisms in an approximately $330 \mathrm{kDa}$ protein are linked to chloroquine-resistant $P$. falciparum in Southeast Asia and Africa. Cell. 1997;91:593-603.

26. Wellems TE, Plowe CV. Chloroquine-resistant malaria. J Infect Dis. 2001;184:770-6.

27. McConnachie K. Boundaries and belonging in the Indo-Myanmar borderlands: Chin refugees in Mizoram. J Refug Stud. 2018;31:314-33.

28. Das SC, Baruah I. Incrimination of Anopheles minimus Theobald and Anopheles balabacensis balabacensis Baisas (A. dirus) as malaria vectors in Mizoram. Indian J Malariol. 1985;22:53-5.

29. Srivastava A, Nagpal BN, Saxena R, Subbarao SK. Predictive habitat modelling for forest malaria vector species An. dirus in India-A GIS-based approach. Curr Sci. 2001;80:1129-34.

30. Zomuanpuii R, Ringngheti L, Brindha S, Gurusubramanian G, Senthil Kumar N. ITS2 characterization and Anopheles species identification of the subgenus Cellia. Acta Trop. 2013;125:309-19.

31. Zomuanpuii R, Guruswami G, Nachimuthu SK. A three year study on distribution and ecology of Anophelines in Thenzawl, Mizoram, India. J Environ Biol. 2014;35:369-76.

32. Gharbi M, Flegg JA, Pradines B, Berenger A, Ndiaye M, Djimde AA, et al. Surveillance of travellers: an additional tool for tracking antimalarial drug resistance in endemic countries. PLOS ONE. 2013;8:e77775.

33. Thomsen TT, Madsen LB, Hansson HH, Tomas EV, Charlwood D, Bygbjerg IC, et al. Rapid selection of Plasmodium falciparum chloroquine resistance transporter gene and multidrug resistance gene-1 haplotypes associated with past chloroquine and present artemether-lumefantrine use in Inhambane District, southern Mozambique. Am J Trop Med Hyg. 2013;88:536-41.

34. Mekonnen SK, Aseffa A, Berhe N, Teklehaymanot T, Clouse RM, Gebru T, et al. Return of chloroquine-sensitive Plasmodium falciparum parasites 
and emergence of chloroquine-resistant Plasmodium vivax in Ethiopia. Malar J. 2014;13:244.

35. Ndam NT, Basco LK, Ngane VF, Ayouba A, Ngolle EM, Deloron P, et al. Reemergence of chloroquine-sensitive pfcrt K76 Plasmodium falciparum genotype in Southeastern Cameroon. Malar J. 2017;16:130.

36. Dagnogo O, Ako AB, Ouattara L, Dago ND, Coulibaly DN, Toure AO, et al. Towards a re-emergence of chloroquine sensitivity in Côte d'Ivoire? Malar J. 2018;17:413.

37. Das S, Tripathy S, Chattopadhayay S, Das B, Kar Mahapatra S, Hati AK, et al. Progressive increase in point mutations associates chloroquine resistance: even after withdrawal of chloroquine use in India. Int J Parasitol Drugs Drug Resist. 2017;7:251-61.

38. Dajem SMB, Al-Farsi HM, Al-Hashami ZS, Al-Sheikh AAH, Al-Qahtani A, Babiker HA. Distribution of drug resistance genotypes in Plasmodium falciparum in an area of limited parasite diversity in Saudi Arabia. Am J Trop Med Hyg. 2012;86:782-8.

39. Ocan M, Akena D, Nsobya S, Kamya MR, Senono R, Kinengyere AA, et al. Persistence of chloroquine resistance alleles in malaria endemic countries: a systematic review of burden and risk factors. Malar J. 2019;18:76.

40. Vinayak S, Mittra P, Sharma YD. Wide variation in microsatellite sequences within each Pfcrt mutant haplotype. Mol Biochem Parasitol. 2006;147:101-8.

41. Vathsala PG, Pramanik A, Dhanasekaran S, Devi CU, Pillai CR, Subbarao SK, et al. Widespread occurrence of the Plasmodium falciparum chloroquine resistance transporter (Pfcrt) gene haplotype SVMNT in P. falciparum malaria in India. Am J Trop Med Hyg. 2004;70:256-9.

42. Bharti PK, Alam MT, Boxer R, Shukla MM, Gautam SP, Sharma YD, et al. Therapeutic efficacy of chloroquine and sequence variation in crt gene among patients with falciparum malaria in central India. Trop Med Int Health. 2010;15:33-40.

43. Mixson-Hayden T, Jain V, McCollum AM, Poe A, Nagpal AC, Dash AP, et al. Evidence of selective sweeps in genes conferring resistance to chloroquine and pyrimethamine in Plasmodium falciparum isolates in India. Antimicrob Agents Chemother. 2010;54:997-1006.

44. Awasthi G, Prasad GB, Das A. Population genetic analyses of Plasmodium falciparum chloroquine receptor transporter gene haplotypes reveal the evolutionary history of chloroquine-resistant malaria in India. Int J Parasitol. 2011:41:705-9.

45. Foote SJ, Kyle DE, Martin RK, Oduola AM, Forsyth K, Kemp DJ, et al. Several alleles of the multidrug-resistance gene are closely linked to chloroquine resistance in Plasmodium falciparum. Nature. 1990;345:255-8.
46. Wootton JC, Feng X, Ferdig MT, Cooper RA, Mu J, Baruch DI, et al. Genetic diversity and chloroquine selective sweeps in Plasmodium falciparum. Nature. 2002;418:320-3.

47. Lumb V, Madan R, Das MK, Rawat V, Dev V, Khan W, et al. Differential genetic hitchhiking around mutant pfcrt alleles in the Indian Plasmodium falciparum population. J Antimicrob Chemother. 2012;67:600-8.

48. Tinto H, Guekoun L, Zongo I, Guiguemde RT, D'Alessandro U, Ouedraogo JB. Chloroquine-resistance molecular markers (pfcrt T76 and Pfmdr-1 Y86) and amodiaquine resistance in Burkina Faso. Trop Med Int Health. 2008;13:238-40.

49. Veiga MI, Dhingra SK, Henrich PP, Straimer J, Gnadig N, Uhlemann AC, et al. Globally prevalent PfMDR1 mutations modulate Plasmodium falciparum susceptibility to artemisinin-based combination therapies. Nat Commun. 2016;7:11553.

50. Mungthin M, Khositnithikul R, Sitthichot N, Suwandittakul N, Wattanaveeradej V, Ward SA, et al. Association between the mdr 1 gene and in vitro artemether and lumefantrine sensitivity in Thai isolates of Plasmodium falciparum. Am J Trop Med Hyg. 2010;83:1005-9.

51. Atroosh WM, Al-Mekhlafi HM, Mahdy MA, Surin J. The detection of pfert and pfmdr1 point mutations as molecular markers of chloroquine drug resistance, Pahang, Malaysia. Malar J. 2012;11:251.

52. Ghanchi NK, Ursing J, Beg MA, Veiga MI, Jafri S, Martensson A. Prevalence of resistance associated polymorphisms in Plasmodium falciparum field isolates from Southern Pakistan. Malar J. 2011;10:18.

53. Huang B, Wang $Q$, Deng C, Wang J, Yang T, Huang $S$, et al. Prevalence of crt and mdr-1 mutations in Plasmodium falciparum isolates from Grande Comore island after withdrawal of chloroquine. Malar J. 2016;15:414.

54. Hemming-Schroeder E, Umukoro E, Lo E, Fung B, Tomás-Domingo P, Zhou $\mathrm{G}$, et al. Impacts of antimalarial drugs on Plasmodium falciparum drug resistance markers, Western Kenya, 2003-2015. Am J Trop Med Hyg. 2018;98:692-9.

\section{Publisher's Note}

Springer Nature remains neutral with regard to jurisdictional claims in published maps and institutional affiliations.
Ready to submit your research? Choose BMC and benefit from:

- fast, convenient online submission

- thorough peer review by experienced researchers in your field

- rapid publication on acceptance

- support for research data, including large and complex data types

- gold Open Access which fosters wider collaboration and increased citations

- maximum visibility for your research: over $100 \mathrm{M}$ website views per year

At BMC, research is always in progress.

Learn more biomedcentral.com/submissions 